\title{
Editorial: The Locus of the Stroop Effect
}

\author{
Benjamin A. Parris ${ }^{1 *}$, Maria Augustinova ${ }^{2}$ and Ludovic Ferrand ${ }^{3}$ \\ ${ }^{1}$ Department of Psychology, Bournemouth University, Poole, United Kingdom, ${ }^{2}$ Normandie Université, UNIROUEN, CRFDP, \\ Rouen, France, ${ }^{3}$ Université Clermont Auvergne, CNRS, LAPSCO, Clermont-Ferrand, France
}

Keywords: Stroop, selective attention, cognitive control, task conflicts, semantic conflict, response conflict

\section{Editorial on the Research Topic}

\section{The Locus of the Stroop Effect}

One of the famous Monty Python's Holy Grail scenes pictures the Knights of the Round attempting to cross the Bridge of Death. After seeing one of his fellow knights failing to answer a challenging question posed by the Bridge keeper and being cast into the Gorge of Eternal Peril, Sir Galahad nervously approaches the Bridge keeper who asks his name, his quest and....his favorite color. Relieved, he answers with ease before being struck by a sense of dread after saying the color "blue." The problem, he realizes as he plummets into the gorge, is that his favorite color is in fact yellow...

Even though individuals failing the requirements of the Stroop task (Stroop, 1935) are spared the dread Sir Galahad experienced, they are often heard self-correcting with some sense of consternation: "blue....no yellow! Arghh!". The Stroop task requires participants to respond quickly to the color a word is printed in whilst at the same time ignoring the meaning of the word itself. The cost of failing to ignore the word is not a plunge into the Gorge of Eternal Peril, but is instead an incorrect response, or more commonly, longer response times compared to when naming the print color of a word that is not color-related (e.g., club in yellow). However, almost 30 years after the publication of MacLeod's (1991) seminal review paper, the locus of this so-called Stroop effect remains unclear. The aim of the present Research Topic was to address this still outstanding question.

When aiming to respond to the color, a participant must focus on that task and once perceived, a semantic representation of the color needs to be activated before the associated word form is retrieved. The Stroop effect suggests that this process can be interrupted by the processing of the to-be-ignored word since the task of word reading is seemingly automatically activated, as is the semantic representation of the word and its word form. Potentially then, amongst other loci, the process of color naming could be interrupted at the level of task set activation, semantic processing, and the word form response. Much of the theory and research however has assumed that the interruption, the locus of the Stroop effect, is at the level of responses (Cohen et al., 1990; Roelofs, 2003), and that it is this type of conflict for which control mechanisms monitor (Botvinick et al., 2001). In line with a recent and burgeoning literature (e.g., Parris, 2014; Levin and Tzelgov, 2016; Augustinova et al., 2018; Entel and Tzelgov, 2018; Kalanthroff et al., 2018; Ferrand et al., 2019; Hasshim et al., 2019; Hershman and Henik, 2019; Parris et al., 2019), the contributions to this Research Topic report findings that indicate that there is more than one locus to the Stroop effect.

Littman et al. review the literature on the physiological and behavioral signatures of task conflict and task control in the Stroop task whilst Hsieh and Sharma invoke task conflict and its (proactive) control to account for a general slowdown in color naming of studied non-color neutral and negative emotional words in the Stroop task. Continuing with the notion that emotion can modify Stroop effects, Berger et al. show that age does not affect the use of proactive control over 
emotion-related Stroop stimuli, but that the nature of the influence of emotion on Stroop effects depends on whether faces or words were the relevant dimension.

The modulating effects of response mode were examined in two contributions. In two experiments, Augustinova et al. report that the locus of interference and facilitation effects might depend on response mode with more types of interference (e.g., task, semantic, and response) and facilitation contributing to the vocal, compared to the manual, response. Highlighting another difference, Mills et al. report a negative priming effect in the vocal (Experiment 1) but not with manual (Experiment 2) Stroop task. The authors argued that this is because it is the actual naming response of the previously ignored stimulus that is suppressed and not the conflict that it generates.

In an fMRI study that controlled for variables that are often confounded, Parris et al. report regions of similar and dissociable neural activity to response and semantic conflict in the Stroop task, whilst Banich summarizes and updates the Cascade-ofControl neural model that argues that there is no single locus to the Stroop effect, and more importantly that the locus might move depending on how well each brain system deals with interference.

In their article, Algom and Chajut argue that the popular "conflict monitoring and control" view of the Stroop effect (Botvinick et al., 2001) fails to account for major Stroop results. Instead, they defend a "data-driven selective attention" view that they argue best accounts for most of Stroop results and one that does not involve higher-order cognitive level processes of control.

\section{REFERENCES}

Augustinova, M., Silvert, S., Spatola, N., and Ferrand, L. (2018). Further investigation of distinct components of Stroop interference and of their reduction by short response stimulus intervals. Acta Psychol. 189, 54-62. doi: 10.1016/j.actpsy.2017.03.009

Botvinick, M. M., Braver, T. S., Barch, D. M., Carter, C. S., and Cohen, J. D. (2001). Conflict monitoring and cognitive control. Psychol. Rev. 108, 624-652. doi: 10.1037//0033-295X.108.3.624

Cohen, J. D., Dunbar, K., and McClelland, J. L. (1990). On the control of automatic processes: a parallel distributed processing account of the Stroop effect. Psychol. Rev. 97:332. doi: 10.1037/0033-295X.97.3.332

Entel, O., and Tzelgov, J. (2018). Focussing on task conflict in the Stroop effect. Psychol. Res. 82, 284-295. doi: 10.1007/s00426-0160832-8

Ferrand, L., Ducrot, S., Chausse, P., Maïonchi-Pino, N., O'Connor, R. J., Parris, B. A., et al. (2019). Stroop interference is a composite phenomenon: evidence from distinct developmental trajectories of its components. Dev. Sci. doi: 10.1111/desc. 12899

Hasshim, N., Downes, M., Bate, S., and Parris, B. A. (2019). Response time distribution analysis of semantic and response interference in a manual response Stroop task. Exp. Psychol. 66, 231-238. doi: 10.1027/1618-3169/a000445

Hershman, R., and Henik, A. (2019). Dissociation between reaction time and pupil dilation in the Stroop task. J. Exp. Psychol. Learn. Mem. Cogn. 45, 1899-1909. doi: $10.1037 /$ xlm0000690

Kalanthroff, E., Davelaar, E., Henik, A., Goldfarb, L., and Usher, M. (2018). Task conflict and proactive control: a computational theory of the Stroop task. Psychol. Rev. 125, 59-82. doi: 10.1037/rev0000083
Much of the work on the locus of the Stroop effect focusses on the conflict that occurs between the two dimensions of the stimulus on the current trial. However, two studies in this Research Topic build on work showing that interference is smaller on the current trial if the previous trial was incongruent; an effect known as the congruency sequence effect (CSE). Ménétré and Laganaro investigate subprocesses involved in the CSE with participants aged from 10 to 80 years old in order to analyze how interference, CSE, and the decomposition of attention and inhibition change across the lifespan. Aschenbrenner and Balota in contrast examine the relationship of the CSE with another measure of control referred to as the item-specific proportion congruency effect (ISPC).

In sum, these studies, reporting differences at behavioral and neurophysiological levels, highlight the loci of the Stroop effect at the level of task set, semantic, and response selection with the modulating effects of emotion and congruency-sequence.

\section{AUTHOR CONTRIBUTIONS}

Each author summarized the articles in the Research Topic that they edited. BP wrote the first draft of the editorial. MA and LF provided comments and recommended amendments.

\section{FUNDING}

This work was part funded by grant ANR-19-CE28-0013-01.

Levin, Y., and Tzelgov, T. (2016). What Klein's "semantic gradient" does and does not really show: decomposing Stroop interference into task and informational conflict components. Front. Psychol. 7:249. doi: 10.3389/fpsyg.2016.00249

MacLeod, C. M. (1991). Half a century of research on the Stroop effect: An integrative review. Psychol. Bull. 109, 163-203.

Parris, B. A. (2014). Task conflict in the Stroop task: when Stroop interference decreases as Stroop facilitation increases in a low task conflict context. Front. Psychol. 5:1182. doi: 10.3389/fpsyg.2014.01182

Parris, B. A., Sharma, D., Weekes, B. S. H., Momenian, M., Augustinova, M., and Ferrand, L. (2019). Response modality and the Stroop task: are there phonological Stroop effects with manual responses? Exp. Psychol. 66, 361-367. doi: $10.1027 / 1618-3169 / \mathrm{a} 000459$

Roelofs, A. (2003). Goal-referenced selection of verbal action: modeling attentional control in the Stroop task. Psychol. Rev. 110, 88-125. doi: 10.1037/0033-295X.110.1.88

Stroop, J. R. (1935). Studies of interference in serial verbal reactions. J. Exp. Psychol. 18, 643-662. doi: 10.1037/h0054651

Conflict of Interest: The authors declare that the research was conducted in the absence of any commercial or financial relationships that could be construed as a potential conflict of interest.

Copyright $\odot 2019$ Parris, Augustinova and Ferrand. This is an open-access article distributed under the terms of the Creative Commons Attribution License (CC BY). The use, distribution or reproduction in other forums is permitted, provided the original author(s) and the copyright owner(s) are credited and that the original publication in this journal is cited, in accordance with accepted academic practice. No use, distribution or reproduction is permitted which does not comply with these terms. 